\title{
Enhanced photocatalytic hydrogen evolution by combining water soluble graphene with cobalt salts
}

\author{
Jing Wang, Ke Feng ${ }^{*}$, Hui-Hui Zhang, Bin Chen, Zhi-Jun Li, Qing-Yuan Meng, \\ Li-Ping Zhang, Chen-Ho Tung and Li-Zhu Wu*
}

\author{
Full Research Paper \\ Address: \\ Key Laboratory of Photochemical Conversion and Optoelectronic \\ Materials, Technical Institute of Physics and Chemistry \& University of \\ Chinese Academy of Sciences, the Chinese Academy of Sciences, \\ Beijing 100190, P. R. China \\ Email: \\ Ke Feng ${ }^{*}$ - kefeng@mail.ipc.ac.cn; Li-Zhu Wu ${ }^{*}$ - Izwu@mail.ipc.ac.cn \\ * Corresponding author \\ Keywords: \\ cobalt salts; earth-abundant catalyst; photocatalysis; photocatalytic \\ hydrogen evolution; water-dispersible sulfonated-graphene
}

Beilstein J. Nanotechnol. 2014, 5, 1167-1174. doi:10.3762/bjnano.5.128

Received: 07 February 2014

Accepted: 02 July 2014

Published: 29 July 2014

This article is part of the Thematic Series "Photocatalysis".

Guest Editor: R. Xu

(C) 2014 Wang et al; licensee Beilstein-Institut.

License and terms: see end of document.

\begin{abstract}
There is tremendous effort put in the pursuit for cheap and efficient catalysts for photocatalytic hydrogen evolution systems. Herein, we report an active catalyst that uses the earth-abundant element cobalt and water-dispersible sulfonated graphene. The photocatalytic hydrogen evolution activity of the catalyst was tested by using triethanolamine (TEOA) as electron donor and eosin Y (EY) as the photosensitizer under LED irradiation at $525 \mathrm{~nm}$. Hydrogen was produced constantly even after $20 \mathrm{~h}$, and the turnover number (TON) reached $148\left(\mathrm{H}_{2} / \mathrm{Co}\right)$ in $4 \mathrm{~h}$ with respect to the initial concentration of the added cobalt salts was shown to be 5.6 times larger than that without graphene.
\end{abstract}

\section{Introduction}

Photocatalytic hydrogen evolution from water-splitting is a long-standing goal for researchers since it can help to supply the growing worldwide energy demand not only environmentally friendly but also sustainably [1-4]. Platinum, the most efficient hydrogen evolution co-catalyst, is rare and expensive, which limits its availability [5]. Hence, developing photocatalytic systems that rely only on earth-abundant elements are desired for making hydrogen a competitive alternative energy source. In recent years, systems based on iron complexes, nickel complexes or molybdenum complexes have been reported as promising candidates for catalyzing the hydrogen evolution [6-15]. Cobalt-based catalysts are particularly attractive catalysts that are easily obtained, environmentally benign and rely on earth-abundant elements [16]. Molecular cobalt catalysts [17], such as polypyridyl complexes [18,19], oxime complexes [20], have been proven to be efficient in the photocatalytic production of hydrogen, and the turnover number (TON) has become higher upon introducing more appropriate ligands. 
Besides, cobalt-based heterogeneous structures are also of interest $[21,22]$. A hybrid $\mathrm{Co}_{\mathrm{h}}-\mathrm{CdTe}$ artificial catalyst for photocatalytic hydrogen evolution [23], for example, was simply constructed in situ from earth-abundant cobalt salts and CdTe quantum dots.

As a new carbon material with large surface area and excellent electrical properties, graphene has raised much attention since 2004 [24-33]. Specifically, graphene has been involved in photocatalytic hydrogen production systems [34], such as $\mathrm{TiO}_{2}-$ (N)RGO-Pt [35-38], g-C ${ }_{3} \mathrm{~N}_{4}$-RGO-Pt [39], CdS-RGO-Pt [4043], $\mathrm{MoS}_{2}$-NRGO [44,45], EY-RGO-Pt [46] and $\mathrm{BiVO}_{4}$-RGO$\mathrm{Ru} / \mathrm{SrTiO}_{3}: \mathrm{Rh}$ [47] (RGO: reduced graphene oxide; EY: eosin Y). Graphene enhances the catalytic efficiency of hydrogen evolution remarkably. By using transient photovoltage and photocurrent techniques [48-50], the function of graphene was examined. More recently, our group has demonstrated the efficient forward electron-transfer mediated by graphene in terms of the unique spectroscopic property of photosensitizer EY [51]. The result stimulated us to explore graphene-based hydrogen evolution systems with earth-abundant co-catalysts.

In the present work, we report a new water-soluble graphene-cobalt-based hydrogen evolution system, showing a 5.6 times higher efficiency than that of the same system without graphene. Herein, sulfonated-graphene $\left(\mathrm{G}-\mathrm{SO}_{3}\right)$, being watersoluble and partially reduced $[52,53]$, serves as a great platform $[41,51]$ to support the catalysts. With TEOA (triethanolamine) as an electron donor, EY as a photosensitizer, $\mathrm{Co}(\mathrm{TEOA})_{2}{ }^{2+}$ is formed in situ and adsorbed at the surface or around the $\mathrm{G}_{-} \mathrm{SO}_{3}$ when cobalt salts and $\mathrm{G}-\mathrm{SO}_{3}$ are introduced into the hydrogen evolution system. Upon irradiation by visible light $(525 \mathrm{~nm}$ LEDs as light source) for $4 \mathrm{~h}$, the system is able to produce hydrogen with a TON up to 148 with the initial concentration of cobalt salts added. And hydrogen constantly evolves even after $20 \mathrm{~h}$ irradiation.

\section{Results and Discussion}

Fourier transform infrared spectroscopy (FTIR) is employed to characterize $\mathrm{GO}$ and $\mathrm{G}_{-} \mathrm{SO}_{3}$. As shown in Figure 1, compared to $\mathrm{GO}, \mathrm{G}_{-} \mathrm{SO}_{3}$ has typical absorptions at 1177,1123 and $1037 \mathrm{~cm}^{-1}$, which are assigned to $v_{\mathrm{S}-\mathrm{O}}$ and $v_{\mathrm{S} \text {-phenyl }}$ confirming the modification of sulfanilic acid on graphene sheets [53]. Meanwhile, peaks attributed to $\mathrm{C}=\mathrm{O}$ in carboxylic acid and carbonyl moieties $\left(v_{\mathrm{C}=\mathrm{O}}\right.$ at $\left.1720 \mathrm{~cm}^{-1}\right), \mathrm{C}-\mathrm{OH}\left(v_{\mathrm{C}-\mathrm{OH}}\right.$ at $1365 \mathrm{~cm}^{-1}$ ) decrease sharply, implying a partial reduction of GO [54].

X-ray photoelectron spectroscopy (XPS) measurements were performed to confirm the differences between $\mathrm{GO}$ and $\mathrm{G}-\mathrm{SO}_{3}$. Five different peaks centered at 284.5, 285.9, 286.6, 287.7 and $288.9 \mathrm{eV}$ appear in the $\mathrm{C} 1 \mathrm{~s}$ deconvolution spectrum of $\mathrm{GO}$, corresponding to $\mathrm{C}=\mathrm{C} / \mathrm{C}-\mathrm{C}$ in aromatic rings, $\mathrm{C}-\mathrm{OH}$ (hydroxy), $\mathrm{C}-\mathrm{O}-\mathrm{C}$ (epoxy), $\mathrm{C}=\mathrm{O}$ (carbonyl), and $\mathrm{C}(\mathrm{O}) \mathrm{O}$ (carboxyl) groups, respectively [55]. For $\mathrm{G}-\mathrm{SO}_{3}$, the peak centered at $284.6 \mathrm{eV}$ becomes narrower, suggesting the partial restoration of the $\pi$-electron network in $\mathrm{G}_{-} \mathrm{SO}_{3}$. Other oxygen-containing carbon peaks, decreased sharply, indicating GO is reduced efficiently.

Further, Raman spectra and X-ray diffraction (XRD) patterns of $\mathrm{GO}$ and $\mathrm{G}-\mathrm{SO}_{3}$ are compared in Figure 2. GO and $\mathrm{G}-\mathrm{SO}_{3}$ both show the characteristic $\mathrm{D}$ band and $\mathrm{G}$ band at $1350 \mathrm{~cm}^{-1}$ and $1597 \mathrm{~cm}^{-1}$, but the enhanced $I_{\mathrm{D}} / I_{\mathrm{G}}$ ratio for $\mathrm{G}-\mathrm{SO}_{3}$ indicates the functionalization and reduction of GO. As confirmed by the XRD patterns, after reduction and functionalization, the $d$-spacing becomes wider since the angle $2 \theta$ shifted to the left from $8.85^{\circ}$ to $6.92^{\circ}$. The decreased intensity, meanwhile, manifests a more disordered structure in $\mathrm{G}-\mathrm{SO}_{3}$. As a result, the obtained $\mathrm{G}-\mathrm{SO}_{3}$ is both reduced and functionalized, which guarantees not only its high conductivity for electron transfer, but also its great dispersibility to act as a platform to anchor catalysts.

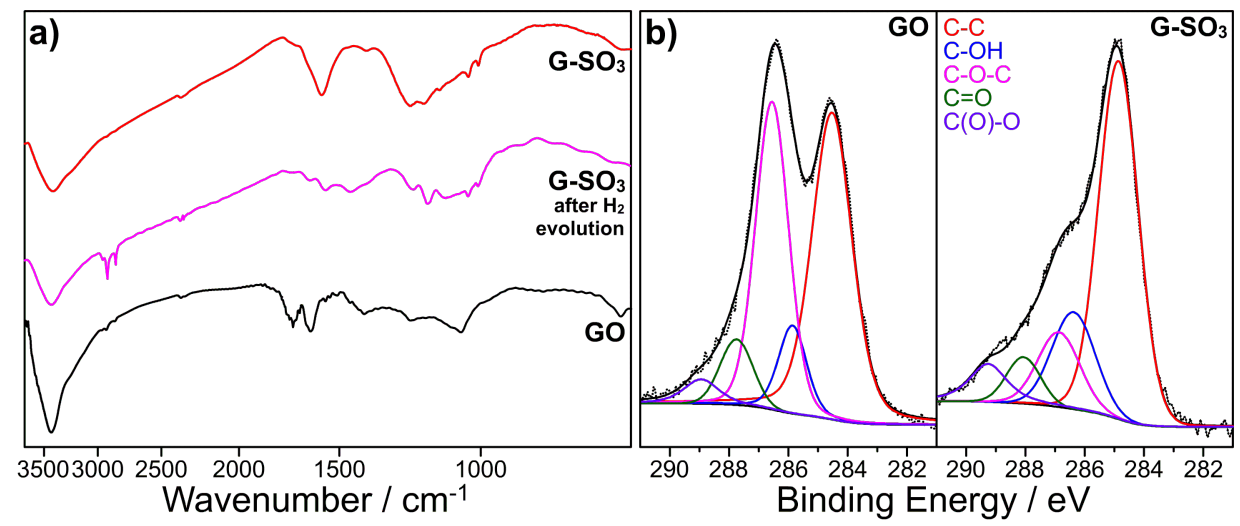

Figure 1: FTIR (a) and XPS (b) spectra of $\mathrm{GO}, \mathrm{G}-\mathrm{SO}_{3}$ and $\mathrm{G}-\mathrm{SO}_{3}$ after photocatalytic hydrogen evolution 


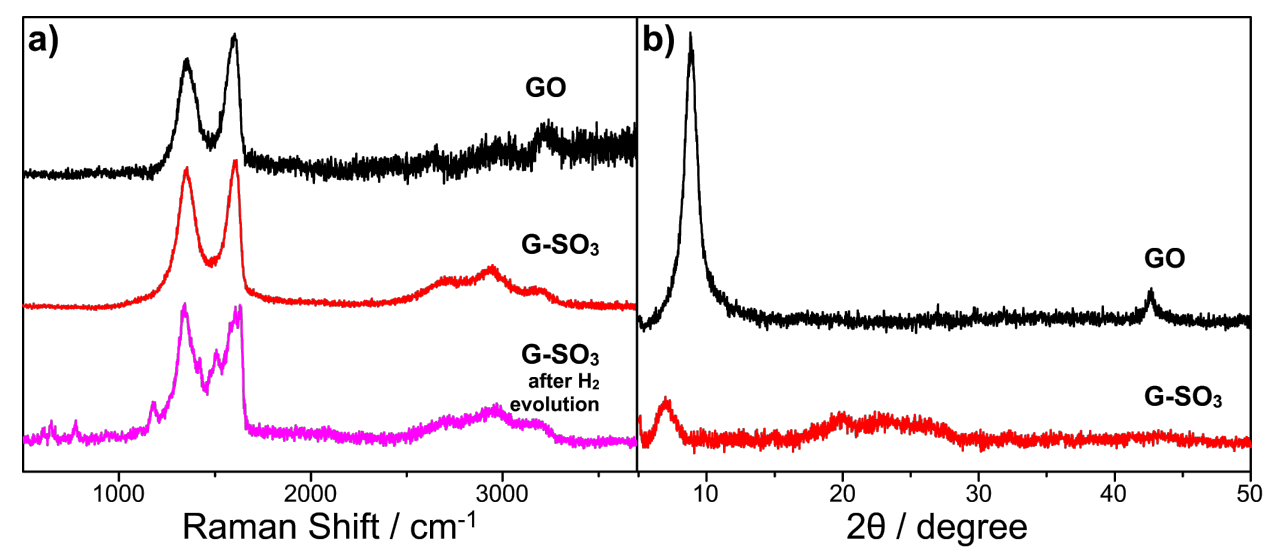

Figure 2: Raman (a) and XRD (b) spectra of GO (black), G-SO 3 (red) and $\mathrm{G}-\mathrm{SO}_{3}$ after photocatalytic hydrogen evolution (purple).

The photocatalytic hydrogen evolution was evaluated under irradiation at $525 \mathrm{~nm}$ by using TEOA as a sacrificial donor and $\mathrm{EY}$ as a photosensitizer, while cobalt salts and $\mathrm{G}-\mathrm{SO}_{3}$ were added to serve as a catalyst in the reaction system (Figure 3 ). It is proposed that $\mathrm{Co}^{2+}$ forms a $\mathrm{Co}(\mathrm{TEOA})_{2}{ }^{2+}$ complex in the presence of TEOA [56]. No significant amounts of hydrogen were detected in the absence of either irradiation or the photosensitizer EY, indicating that hydrogen was produced through the photochemical reaction. Evidently, Co(TEOA) ${ }_{2}{ }^{2+}$ complexes can function as catalysts to reduce protons to hydrogen, similar to the observations of Sun and coworkers [57]. When $\mathrm{G}-\mathrm{SO}_{3}$ was introduced, the amount of hydrogen obviously increased. Because our previous work [51] has demonstrated that $\mathrm{G}_{-} \mathrm{SO}_{3}$ acts as an electron mediator of $\mathrm{EY}$ and platinum nanoparticles co-catalyst, we consider that in the current study the electron transfer process from the EY radical anion $\left(\mathrm{EY}^{\cdot-}\right)$ to $\mathrm{G}-\mathrm{SO}_{3}$ or in situ formed-Co(TEOA $)_{2}{ }^{2+}$ would be facilitated. Similar to the storage phenomenon observed in carbon nanotubes, a small fraction of the electrons may get stored in graphene sheets, thus making graphene an electron reservoir to continuously provide electrons to the catalytic center [58-60]. The positive synergetic effect consequently enhances the photocatalytic activity for hydrogen evolution of the system. To examine any counter anion effects, we further used four different kinds of cobalt salts in our photocatalytic hydrogen evolution system: cobalt chloride, cobalt nitrate, cobalt perchlorate and cobalt acetate. The amounts of evolved hydrogen in each system did not differ much, indicating that the catalytic behavior is independent of the anions used. The results also manifest the formation of $\mathrm{Co}(\mathrm{TEOA})_{2}{ }^{2+}$ catalysts in the systems.

The $\mathrm{pH}$ value of the solution greatly influences the hydrogen evolution process of the system. The system performed well over a wide range ( $\mathrm{pH} 8-12)$, reaching a maximal turnover at pH 10.86 (Supporting Information File 1, Figure S1). However, when $\mathrm{pH}$ value was below 7.2 , there was no detectable hydrogen produced from the system. This $\mathrm{pH}$-dependency is due to a
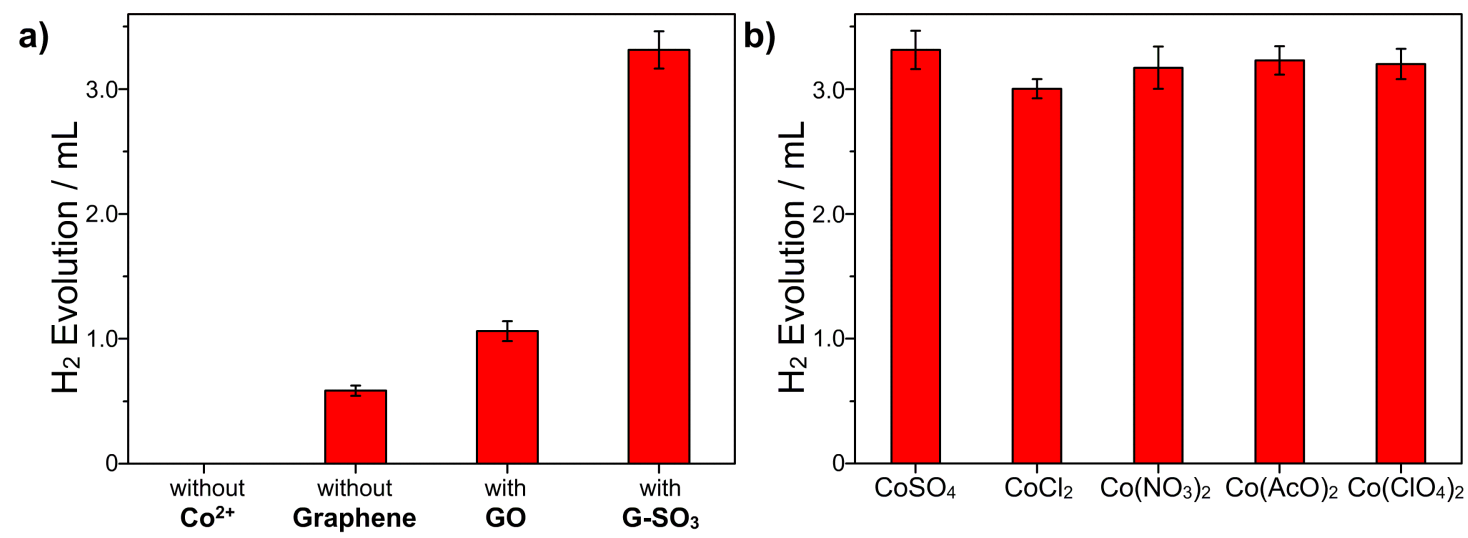

Figure 3: Photocatalytic hydrogen evolution with different graphene (a) and cobalt salts (b) at $\mathrm{pH} 10.86$ in $\mathrm{H}_{2} \mathrm{O}$ after $4 \mathrm{~h}$; sample concentration: Co ${ }^{2+}$ $\left(2.0 \times 10^{-4} \mathrm{~mol} / \mathrm{L}\right)$, graphene $(0.04 \mathrm{mg} / \mathrm{mL})$, EY $\left(4.0 \times 10^{-4} \mathrm{~mol} / \mathrm{L}\right)$ and TEOA $(0.2 \mathrm{~mol} / \mathrm{L})$. 
number of factors: in acidic medium, the protonation of TEOA inevitably results in a poor electron-donating ability and less $\mathrm{Co}(\mathrm{TEOA})_{2}{ }^{2+}$ catalyst is formed. In a basic solution, the graphene dispersion was more stable and the light absorption of EY is stronger but the concentration of protons is too low.

To optimize the hydrogen evolution system, four sets of experiments were carried out: varying the concentration of $\mathrm{CoSO}_{4}$, $\mathrm{G}_{-} \mathrm{SO}_{3}$, EY and TEOA used while keeping a constant concentration of the other three components at $\mathrm{pH} 10.86$. The results of these experiments are shown in Figure 4. With the addition of $\mathrm{G}-\mathrm{SO}_{3}$, even at low concentrations, the amount of hydrogen evolution showed a remarkable increase and reached a maximum of $3.31 \mathrm{~mL}$, which is 5.6 times larger than that of the system without $\mathrm{G}_{-} \mathrm{SO}_{3}$. Further increasing the concentration of $\mathrm{G}-\mathrm{SO}_{3}$ resulted in a decrease in the amount of hydrogen generated. This phenomenon happened in many other reported works, which can be explained by the light shielding effect of graphene [61-63]. Varying the concentration of $\mathrm{CoSO}_{4}$, a similar tendency was observed. The concentration of EY also exercises a great influence on catalytic performance of the system. The amount of hydrogen evolution increases with the concentration of EY linearly when the concentration of EY is below $0.4 \mathrm{mM}$. After a further increase of the EY concentration to $0.8 \mathrm{mM}$ or $1.6 \mathrm{mM}$, however, the amount of hydrogen still increases but at a relatively slower rate. This is because self-quenching and shield-effects inevitably decrease the ability of EY to act as the photosensitizer [64]. As for the electron donor TEOA, the highest hydrogen evolution efficiency was obtained at a concentration of 0.2 M. Figure S2 in Supporting Information File 1 shows the kinetic curve of the photocatalytic hydrogen evolution under the optimized conditions at $\mathrm{pH} 10.86$ (the concentration of $\mathrm{CoSO}_{4}, \mathrm{G}_{-} \mathrm{SO}_{3}, \mathrm{EY}$ and TEOA are $2.0 \times 10^{-4} \mathrm{~mol} / \mathrm{L}$, $0.04 \mathrm{mg} / \mathrm{mL}, 4.0 \times 10^{-4} \mathrm{~mol} / \mathrm{L}$ and $0.2 \mathrm{~mol} / \mathrm{L}$, respectively). The total amount of hydrogen evolved under LED irradiation at $525 \mathrm{~nm}$ was about $3.31 \mathrm{~mL}(148 \mu \mathrm{mol})$ and the TON reached 148 with respect to the initial concentration of cobalt. More hydrogen was produced from the system after prolonged irradiation times but at a slower rate. The reason for the decreased rate at longer irradiation times is attributed to the decomposition of EY. As described in our previous work [51], EY decomposes to fluorescein, which has a lower absorption but a higher stability. To confirm the result in the current study, we carried out control experiments that used fluorescein as photosensitizer a)

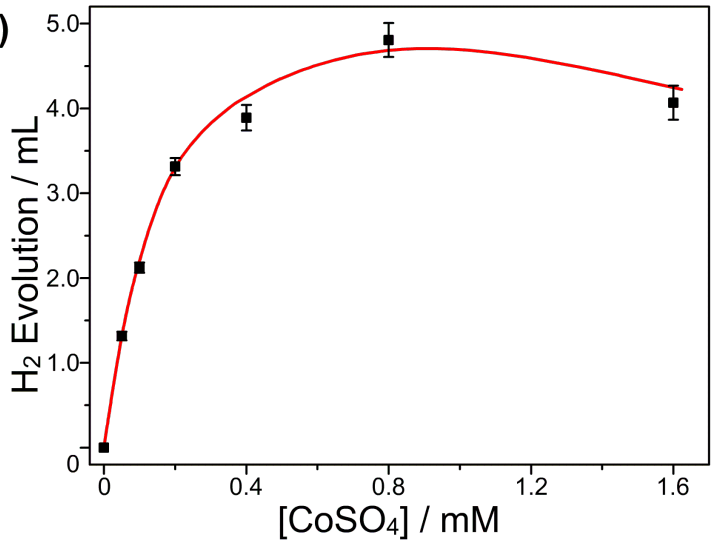

c)

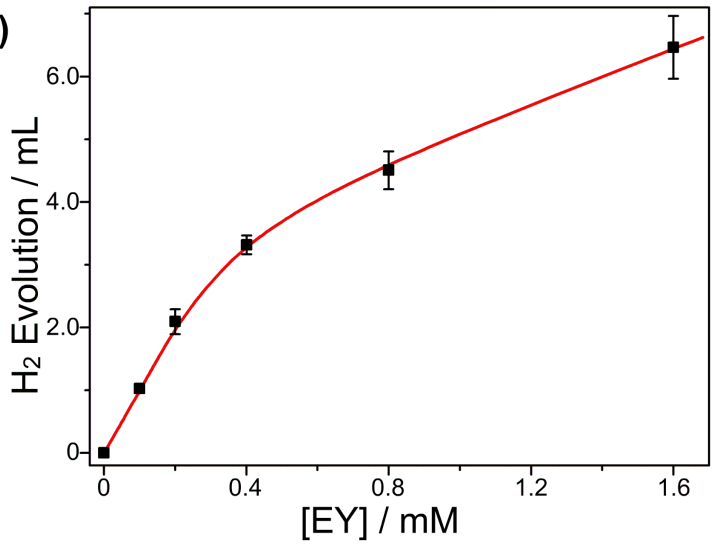

b)
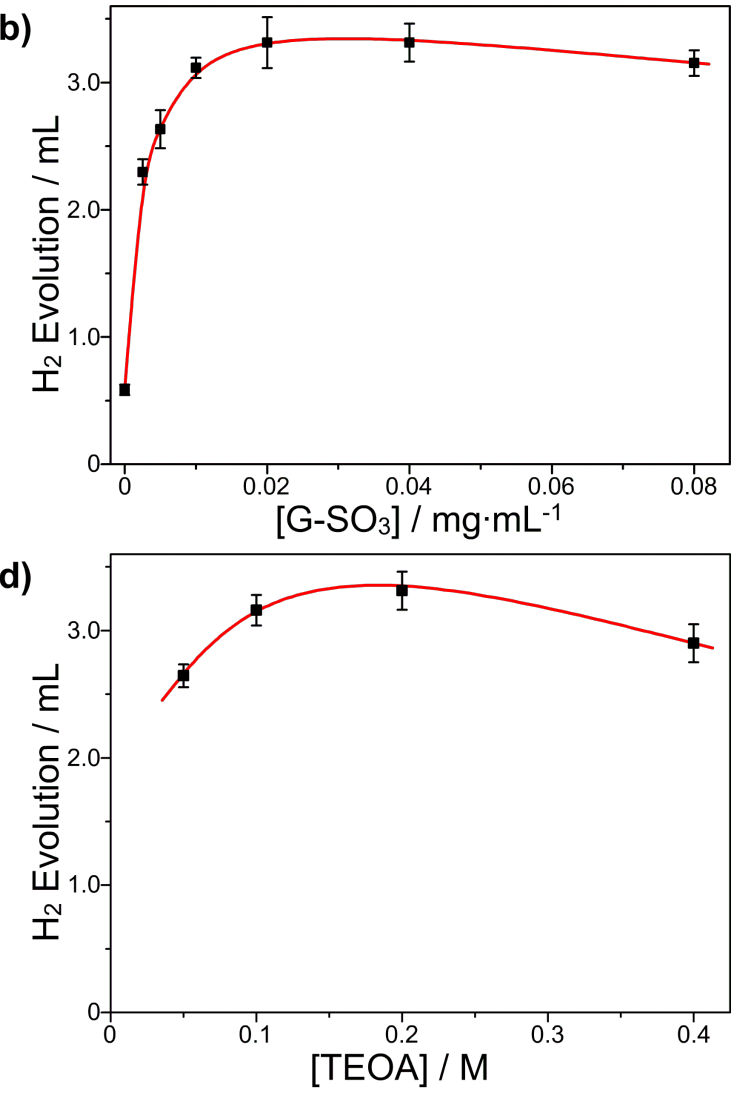

Figure 4: Photocatalytic hydrogen evolution as a function of the $\mathrm{CoSO}_{4}(\mathrm{a}), \mathrm{G}-\mathrm{SO}_{3}$ (b), $\mathrm{EY}$ (c) and TEOA (d) concentration at pH 10.86 in $\mathrm{H}_{2} \mathrm{O}$ after $4 \mathrm{~h}$; other sample concentration: $\mathrm{CoSO}_{4}\left(2.0 \times 10^{-4} \mathrm{~mol} / \mathrm{L}\right), \mathrm{G}-\mathrm{SO}_{3}(0.04 \mathrm{mg} / \mathrm{mL}), \mathrm{EY}\left(4.0 \times 10^{-4} \mathrm{~mol} / \mathrm{L}\right)$ and TEOA $(0.2 \mathrm{~mol} / \mathrm{L})$. 
for hydrogen evolution under the identical condition. As shown in Supporting Information File 1, Figure S2, the rate of hydrogen evolution is the same as that of the EY system after $1 \mathrm{~h}$ of irradiation.

It is worth noting that after irradiation, a black magnetic precipitate was observed and adsorbed on the magnetron in both cases with or without $\mathrm{G}-\mathrm{SO}_{3}$. When rinsed with acetone more than three times, the precipitation was visualized by TEM (transmission electron microscopy). As shown in Figure 5, in the absence of $\mathrm{G}-\mathrm{SO}_{3}$ nanoparticles aggregated in size of about hundreds nanometers. Each particle is composed of lots of small nanoparticles of several nanometers in diameter. The lattice fringes in the HRTEM (high resolution TEM) images suggest a welldefined crystal structure. The lattice spacing of about 0.191 and $0.203 \mathrm{~nm}$ can be assigned to the (101) and (002) planes of metallic cobalt $\mathrm{Co}$, space group $P_{63} / m m c$ (JCPDS card 05-0727). When $\mathrm{G}_{-} \mathrm{SO}_{3}$ was added, the TEM images exhibited much difference. Firstly, nanoparticles were formed but dispersed on $\mathrm{G}_{-} \mathrm{SO}_{3}$ sheets instead. Secondly, the sizes of the nanoparticles were smaller. The HRTEM image also showed the lattice fringes, and the lattice spacing $(0.191$ and $0.203 \mathrm{~nm})$ is consistent with those observed in the system without $\mathrm{G}_{-} \mathrm{SO}_{3}$. This phenomenon indicated that $\mathrm{G}-\mathrm{SO}_{3}$ provides a platform to support cobalt catalysts, and at the same time $\mathrm{G}-\mathrm{SO}_{3}$ avoids the aggregation of the catalyst to some extent. These results are consistent with the better performance and the higher hydrogen evolution from the system with $\mathrm{G}-\mathrm{SO}_{3}$.

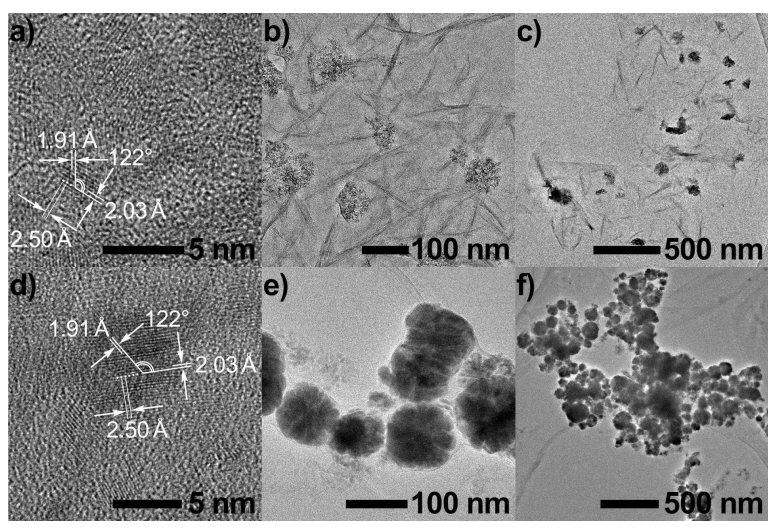

Figure 5: The TEM images nanoparticles after irradiation with $(a-c)$ or without (d-f) $\mathrm{G}-\mathrm{SO}_{3}$.

As mentioned above, the TEM results showed that cobalt metal nanoparticles may form during the process in both cases. XPS and ICP-MS (inductively coupled plasma mass spectrometry) were used to further investigate the magnetic precipitates obtained after the hydrogen evolution reaction. XPS spectra of the precipitates with or without $\mathrm{G}-\mathrm{SO}_{3}$ showed the same peak pattern and location in the range from 776 to $810 \mathrm{eV}$, corresponding to the Co $2 p$ orbital (Supporting Information File 1, Figure S3). The cobalt lines in the spectra, however, were assigned to cobalt(II) [65], not to cobalt(0). This is different from the TEM results and in contrast to the grown cobalt metal nanoparticles on graphene [66]. ICP-MS measurements were carried out by using the precipitates obtained from the system, which gave a cobalt content of $11.1 \%$ (with graphene) and $45.0 \%$ (without graphene), respectively. Either of these results was much higher than that calculated from XPS $(3.8 \%$ and $20.8 \%$ ). In consideration of the fact that XPS probes only a few nanometers below the surface, the discrepancy was tentatively interpreted to be because of $\mathrm{Co}^{2+}$ complexes around the cobalt metal particles, which hinder the effective detection of Co metal in XPS but allows its measurement with ICP-MS. In addition, FTIR spectra of $\mathrm{G}_{-} \mathrm{SO}_{3}$ (Figure 1a, purple line) showed a typical C-H stretching vibration at $2918 \mathrm{~cm}^{-1}$ after photocatalytic hydrogen evolution, which apparently comes from the catalytic $\mathrm{Co}^{\mathrm{II}}(\mathrm{TEOA})_{2}$ species on the surface of $\mathrm{G}_{-} \mathrm{SO}_{3}$.

Cyclic voltammetry (CV) spectra were used to investigate the hydrogen evolution system (Figure 6). And the results showed that $\mathrm{Co}(\mathrm{TEOA})_{2}{ }^{2+}$ complex was active for electrocatalytic hydrogen evolution in $0.2 \mathrm{M} \mathrm{K}_{2} \mathrm{SO}_{4}$ and $0.4 \mathrm{M}$ TEOA aqueous solution. The $\mathrm{Co}^{\mathrm{II}}(\mathrm{TEOA})_{2} / \mathrm{Co}^{\mathrm{I}}(\mathrm{TEOA})_{2}$ reduction band peaked at about $-1.1 \mathrm{~V}$ (vs SCE), and is followed by a rapid rise in current at $-1.25 \mathrm{~V}$ (vs SCE). This increase of current, accompanied by the evolution of bubbles, can be attributed to the catalytic generation of hydrogen from the aqueous solution [67]. In order to verify that $\mathrm{Co}(\mathrm{TEOA})_{2}{ }^{2+}$ is responsible for the catalysis, control experiments were performed at room temperature. When the $0.2 \mathrm{M} \mathrm{K}_{2} \mathrm{SO}_{4}$ aqueous solution or $0.2 \mathrm{M} \mathrm{K}_{2} \mathrm{SO}_{4}$ and $0.4 \mathrm{M}$ TEOA aqueous solution were studied, no catalytic current appeared until the potential was over $-1.5 \mathrm{~V}$ (vs SCE). When $\mathrm{G}-\mathrm{SO}_{3}$ was added, no new peak emerged, but the catalytic current intensity increased by about $20 \%$. The observation implied that in the presence of $\mathrm{G}-\mathrm{SO}_{3}$, electron transfer processes become faster, which results in a higher activity toward electrocatalytic hydrogen evolution. Analogously, $\mathrm{G}-\mathrm{SO}_{3}$ is important for enhancing the performance of photocatalytic hydrogen evolution. For photocatalytic hydrogen evolution systems, the photosensitizer EY is often reduced by TEOA to form $\mathrm{EY}^{\bullet-}$ radical anions. Since the oxidation potential of $\mathrm{EY}^{\bullet-}(-1.05 \mathrm{~V}$ vs NHE) [68] is more negative than that of $\mathrm{Co}^{\mathrm{II}}(\mathrm{TEOA})_{2} / \mathrm{Co}^{\mathrm{I}}(\mathrm{TEOA})_{2}$ couple, an electron transfer from $\mathrm{EY}^{\bullet-}$ to cobalt-center is thermodynamically feasible and initiates the whole hydrogen evolution process.

Taking into consideration all results of the TEM, XPS, ICP-MS and $\mathrm{CV}$ measurements, the photocatalytic process in this work can be described in Scheme 1. When all the components 


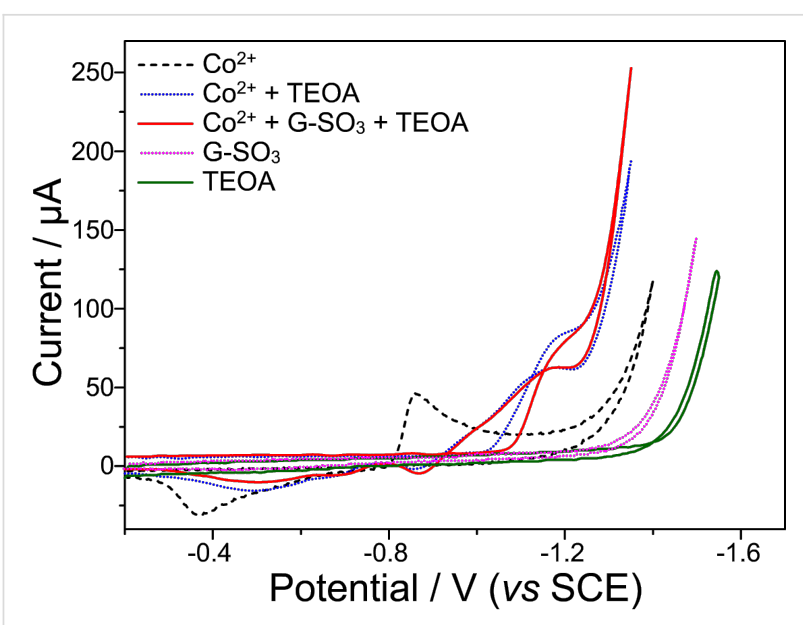

Figure 6: CV spectra of the $4.0 \times 10^{-3} \mathrm{~mol} / \mathrm{L} \mathrm{CoSO}_{4}+0.2 \mathrm{~mol} / \mathrm{L}$ $\mathrm{K}_{2} \mathrm{SO}_{4}$ solution (black), $4.0 \times 10^{-3} \mathrm{~mol} / \mathrm{L} \mathrm{CoSO}_{4}+0.4 \mathrm{~mol} / \mathrm{L} \mathrm{TEOA}+$ $0.2 \mathrm{~mol} / \mathrm{L} \mathrm{K}_{2} \mathrm{SO}_{4}$ solution (blue), $4.0 \times 10^{-3} \mathrm{~mol}^{2} \mathrm{~L} \mathrm{CoSO}_{4}+0.4 \mathrm{~mol} / \mathrm{L}$ $\mathrm{TEOA}+0.04 \mathrm{mg} / \mathrm{mL} \mathrm{G}-\mathrm{SO}_{3}$ solution + $0.2 \mathrm{~mol} / \mathrm{L} \mathrm{K}_{2} \mathrm{SO}_{4}$ (red), $0.04 \mathrm{mg} / \mathrm{mL} \mathrm{G}-\mathrm{SO}_{3}$ solution $+0.2 \mathrm{~mol} / \mathrm{L} \mathrm{K}_{2} \mathrm{SO}_{4}$ (purple) and $0.4 \mathrm{~mol} / \mathrm{L}$ $\mathrm{TEOA}+0.2 \mathrm{~mol} / \mathrm{L} \mathrm{K}_{2} \mathrm{SO}_{4}$ solution (green).

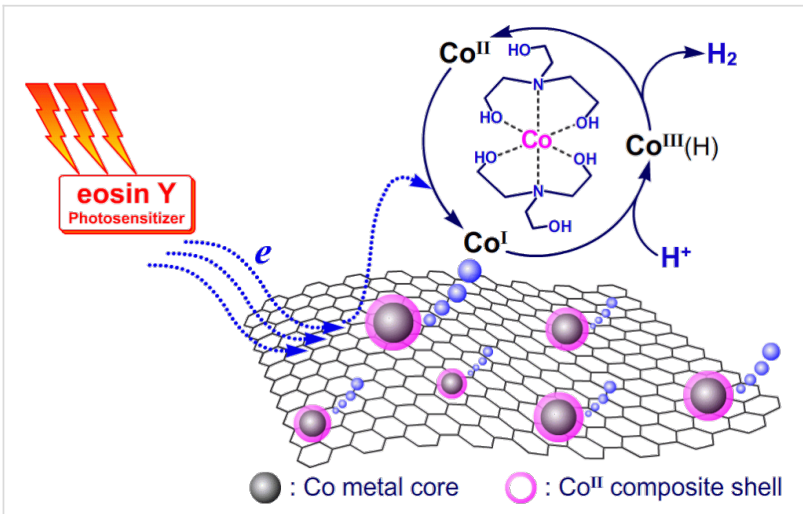

Scheme 1: Schematic illustration of the photocatalytic hydrogen evolution process.

(TEOA, EY, G-SO $3, \mathrm{CoSO}_{4}$ ) were added into the reaction system, $\mathrm{Co}^{\mathrm{II}}(\mathrm{TEOA})_{2}$ complexes were formed in situ and are at well-adsorbed or surround the $\mathrm{G}_{-} \mathrm{SO}_{3}$. In fact, not all of the $\mathrm{Co}^{\mathrm{II}}(\mathrm{TEOA})_{2}$ complexes were on the surface of $\mathrm{G}_{-} \mathrm{SO}_{3}$, because ICP-MS measurements gave a cobalt content of $11.1 \%$, which was much lower than the feeding ratio of $22.8 \%$. Upon irradiation, the electrons of the $\mathrm{EY}^{{ }^{-}-}$radical anion generated from EY and TEOA, transfer to G-SO 3 or directly to $\mathrm{Co}^{\mathrm{II}}$ (TEOA) $)_{2}$ to initiate the catalytic hydrogen evolution. Since graphene is an ideal electron acceptor and/or electron reservoir, an efficient multi-electron transfer toward the catalytic center $\mathrm{Co}^{\mathrm{II}}(\mathrm{TEOA})_{2}$ takes place. Regarding the reports about photocatalytic hydrogen evolution systems based on molecular cobalt complexes in the literature [20], it could be speculated that in the present work the reduction of $\mathrm{Co}^{\mathrm{II}}(\mathrm{TEOA})_{2}$ to $\mathrm{Co}^{\mathrm{I}}(\mathrm{TEOA})_{2}$ occurs firstly. $\mathrm{Co}^{\mathrm{I}}(\mathrm{TEOA})_{2}$, on the one hand, can be protonated to form
$\mathrm{Co}^{\mathrm{III}}(\mathrm{TEOA})_{2} \mathrm{H}$ hydride, which reacts with another hydride to eliminate hydrogen or further protonated to release hydrogen and $\mathrm{Co}^{\mathrm{III}}(\mathrm{TEOA})_{2}$, which is subsequently reduced to $\mathrm{Co}^{\mathrm{II}}(\mathrm{TEOA})_{2}$ for the next catalytic circulation. On the other hand, the protonated $\mathrm{Co}^{\mathrm{III}}(\mathrm{TEOA})_{2} \mathrm{H}$ can also be reduced further to yield $\mathrm{Co}^{\mathrm{II}}(\mathrm{TEOA})_{2} \mathrm{H}$ hydride, which experienced the above cycle for hydrogen evolution. Specifically, if the $\mathrm{Co}^{\mathrm{I}}(\mathrm{TEOA})_{2}$ species is not protonated at low concentrations of protons in the system, it can be reduced further to $\mathrm{Co}^{0}(\mathrm{TEOA})_{2}$ [69]. Since there are ligands around $\mathrm{Co}^{0}(\mathrm{TEOA})_{2}$, this $\mathrm{Co}^{0}(\mathrm{TEOA})_{2}$ species can be protonated to form $\mathrm{Co}^{\mathrm{II}}(\mathrm{TEOA})_{2} \mathrm{H}$ that would either eliminate hydrogen as discussed above or release ligands to form metallic cobalt. The obtained metallic cobalt may function as nucleation center anchoring other cobaltcatalysts.

\section{Conclusion}

In summary, we introduce a new water-soluble graphenecobalt-based hydrogen evolution system. With TEOA as the electron donor, EY as the photosensitizer, $\mathrm{Co}(\mathrm{TEOA})_{2}{ }^{2+}$ formed in situ from cobalt salts and TEOA on the surface of G-SO $\mathrm{S}_{3}$ or around it as the initial catalyst, the effective hydrogen evolution system is established. By using $525 \mathrm{~nm}$ LEDs as the light source, this system shows a 5.6 times higher efficiency than that of the same system without $\mathrm{G}-\mathrm{SO}_{3}$, and the hydrogen can continually evolve even after $20 \mathrm{~h}$. With TEM, ICP-MS, and XPS measurements the magnetic precipitation after irradiation is confirmed to be Co metal surrounded by $\mathrm{Co}^{2+}$ species. $\mathrm{CV}$ results indicate the redox potential for the $\mathrm{Co}^{\mathrm{II}}(\mathrm{TEOA})_{2} / \mathrm{Co}^{\mathrm{I}}(\mathrm{TEOA})_{2}$, manifesting the feasible electron transfer process thermodynamically. The effects of the $\mathrm{pH}$ value, as well as the concentration of $\mathrm{G}_{-} \mathrm{SO}_{3}, \mathrm{CoSO}_{4}$ and TEOA were investigated in detail not only to optimize the catalytic activity for hydrogen evolution but also to understand the reaction mechanism. The enhanced activity of the photocatalytic system makes it attractive to design and synthesize new catalysts by using graphene and earth-abundant metal salts for the photocatalytic $\mathrm{H}_{2}$ production.

\section{Supporting Information}

\section{Supporting Information File 1}

Experimental part.

[http://www.beilstein-journals.org/bjnano/content/ supplementary/2190-4286-5-128-S1.pdf]

\section{Acknowledgements}

This work was supported by the Ministry of Science and Technology of China (2014CB239402, 2013CB834505 and 2013CB834804), the National Natural Science Foundation of 
China $(21372232,21090343,91027041,21390404$ and 51373193), and the Chinese Academy of Sciences.

\section{References}

1. McKone, J. R.; Lewis, N. S.; Gray, H. B. Chem. Mater. 2013, 26, 407-414. doi:10.1021/cm4021518

2. Armaroli, N.; Balzani, V. Angew. Chem., Int. Ed. 2007, 46, 52-66. doi:10.1002/anie.200602373

3. Cook, T. R.; Dogutan, D. K.; Reece, S. Y.; Surendranath, Y.; Teets, T. S.; Nocera, D. G. Chem. Rev. 2010, 110, 6474-6502. doi:10.1021/cr100246c

4. Armaroli, N.; Balzani, V. ChemSusChem 2011, 4, 21-36. doi:10.1002/cssc.201000182

5. Harinipriya, S.; Sangaranarayanan, M. V. Langmuir 2002, 18, 5572-5578. doi:10.1021/la025548t

6. Li, Z.-J.; Wang, J.-J.; Li, X.-B.; Fan, X.-B.; Meng, Q.-Y.; Feng, K.; Chen, B.; Tung, C.-H.; Wu, L.-Z. Adv. Mater. 2013, 25, 6613-6618. doi:10.1002/adma.201370283

7. Han, Z.; Qiu, F.; Eisenberg, R.; Holland, P. L.; Krauss, T. D. Science 2012, 338, 1321-1324. doi:10.1126/science.1227775

8. Nippe, M.; Khnayzer, R. S.; Panetier, J. A.; Zee, D. Z.; Olaiya, B. S.; Head-Gordon, M.; Chang, C. J.; Castellano, F. N.; Long, J. R. Chem. Sci. 2013, 4, 3934-3945. doi:10.1039/c3sc51660a

9. Wen, F.; Li, C. Acc. Chem. Res. 2013, 46, 2355-2364. doi:10.1021/ar300224u

10. Ran, J.; Zhang, J.; Yu, J.; Jaroniec, M.; Qiao, S. Z. Chem. Soc. Rev. 2014, in press. doi:10.1039/c3cs60425j

11. Kong, D.; Cha, J. J.; Wang, H.; Lee, H. R.; Cui, Y. Energy Environ. Sci. 2013, 6, 3553-3558. doi:10.1039/c3ee42413h

12. Du, P.; Eisenberg, R. Energy Environ. Sci. 2012, 5, 6012-6021. doi:10.1039/C2EE03250C

13. Thoi, V. S.; Sun, Y.; Long, J. R.; Chang, C. J. Chem. Soc. Rev. 2013, 42, 2388-2400. doi:10.1039/c2cs35272a

14. Wang, M.; Sun, L. ChemSusChem 2010, 3, 551-554. doi:10.1002/cssc.201000062

15. Wang, F.; Wang, W.-G.; Wang, H.-Y.; Si, G.; Tung, C.-H.; Wu, L.-Z. ACS Catal. 2012, 2, 407-416. doi:10.1021/cs200458b

16. Losse, S.; Vos, J. G.; Rau, S. Coord. Chem. Rev. 2010, 254, 2492-2504. doi:10.1016/j.ccr.2010.06.004

17. Natali, M.; Luisa, A.; lengo, E.; Scandola, F. Chem. Commun. 2014, 50, 1842-1844. doi:10.1039/c3cc48882a

18. Bachmann, C.; Guttentag, M.; Spingler, B.; Alberto, R. Inorg. Chem. 2013, 52, 6055-6061. doi:10.1021/ic4004017

19. Guttentag, M.; Rodenberg, A.; Bachmann, C.; Senn, A.; Hamm, P.; Alberto, R. Dalton Trans. 2013, 42, 334-337. doi:10.1039/c2dt31699d

20. Dempsey, J. L.; Brunschwig, B. S.; Winkler, J. R.; Gray, H. B. Acc. Chem. Res. 2009, 42, 1995-2004. doi:10.1021/ar900253e

21. Huang, J.; Mulfort, K. L.; Du, P.; Chen, L. X. J. Am. Chem. Soc. 2012, 134, 16472-16475. doi:10.1021/ja3062584

22. Cao, S.-W.; Liu, X.-F.; Yuan, Y.-P.; Zhang, Z.-Y.; Fang, J.; Loo, S. C. J.; Barber, J.; Sum, T. C.; Xue, C. Phys. Chem. Chem. Phys. 2013, 15, 18363-18366. doi:10.1039/c3cp53350f

23. Li, Z.-J.; Li, X.-B.; Wang, J.-J.; Yu, S.; Li, C.-B.; Tung, C.-H.; Wu, L.-Z. Energy Environ. Sci. 2013, 6, 465-469. doi:10.1039/C2EE23898E

24. Chen, D.; Zhang, H.; Liu, Y.; Li, J. Energy Environ. Sci. 2013, 6, 1362-1387. doi:10.1039/c3ee23586f

25. Li, D.; Kaner, R. B. Science 2008, 320, 1170-1171. doi:10.1126/science. 1158180
26. Novoselov, K. S.; Geim, A. K.; Morozov, S. V.; Jiang, D.; Zhang, Y.; Dubonos, S. V.; Grigorieva, I. V.; Firsov, A. A. Science 2004, 306, 666-669. doi:10.1126/science.1102896

27. Loh, K. P.; Bao, Q.; Ang, P. K.; Yang, J. J. Mater. Chem. 2010, 20 , 2277-2289. doi:10.1039/b920539j

28. Bolotin, K. I.; Sikes, K. J.; Jiang, Z.; Klima, M.; Fudenberg, G.; Hone, J.; Kim, P.; Stormer, H. L. Solid State Commun. 2008, 146, 351-355. doi:10.1016/j.ssc.2008.02.024

29. Stoller, M. D.; Park, S.; Zhu, Y.; An, J.; Ruoff, R. S. Nano Lett. 2008, 8, 3498-3502. doi:10.1021/nl802558y

30. Park, S.; Ruoff, R. S. Nat. Nanotechnol. 2009, 4, 217-224. doi:10.1038/nnano.2009.58

31. Huang, X.; Qi, X.; Boey, F.; Zhang, H. Chem. Soc. Rev. 2012, 41, 666-686. doi:10.1039/c1cs15078b

32. Liu, Y.; Dong, X.; Chen, P. Chem. Soc. Rev. 2012, 41, 2283-2307. doi:10.1039/c1cs15270j

33. Xu, C.; Xu, B.; Gu, Y.; Xiong, Z.; Sun, J.; Zhao, X. Energy Environ. Sci. 2013, 6, 1388-1414. doi:10.1039/c3ee23870a

34. Xie, G.; Zhang, K.; Guo, B.; Liu, Q.; Fang, L.; Gong, J. R. Adv. Mater. 2013, 25, 3820-3839. doi:10.1002/adma.201301207

35. Zhang, X.-Y.; Li, H.-P.; Cui, X.-L.; Lin, Y. J. Mater. Chem. 2010, 20 , 2801-2806. doi:10.1039/b917240h

36. Fan, W.; Lai, Q.; Zhang, Q.; Wang, Y. J. Phys. Chem. C 2011, 115, 10694-10701. doi:10.1021/jp2008804

37. Pei, F.; Liu, Y.; Xu, S.; Lü, J.; Wang, C.; Cao, S. Int. J. Hydrogen Energy 2013, 38, 2670-2677. doi:10.1016/j.ijhydene.2012.12.045

38. Jiang, B.; Tian, C.; Pan, Q.; Jiang, Z.; Wang, J.-Q.; Yan, W.; Fu, H. J. Phys. Chem. C 2011, 115, 23718-23725. doi:10.1021/jp207624x

39. Xiang, Q.; Yu, J.; Jaroniec, M. J. Phys. Chem. C 2011, 115, 7355-7363. doi:10.1021/jp200953k

40. Fang, Z.; Wang, Y.; Song, J.; Sun, Y.; Zhou, J.; Xu, R.; Duan, H. Nanoscale 2013, 5, 9830-9838. doi:10.1039/c3nr03043a

41. Lv, X. J.; Fu, W. F.; Chang, H. X.; Zhang, H.; Cheng, J. S.; Zhang, G. J.; Song, Y.; Hu, C. Y.; Li, J. H. J. Mater. Chem. 2012, 22, 1539-1546. doi:10.1039/c1jm14502a

42. Khan, Z.; Chetia, T. R.; Vardhaman, A. K.; Barpuzary, D.; Sastri, C. V.; Qureshi, M. RSC Adv. 2012, 2, 12122-12128. doi:10.1039/c2ra21596a

43. Li, Q.; Guo, B.; Yu, J.; Ran, J.; Zhang, B.; Yan, H.; Gong, J. R. J. Am. Chem. Soc. 2011, 133, 10878-10884. doi:10.1021/ja2025454

44. Xiang, Q.; Yu, J.; Jaroniec, M. J. Am. Chem. Soc. 2012, 134, 6575-6578. doi:10.1021/ja302846n

45. Maitra, U.; Gupta, U.; De, M.; Datta, R.; Govindaraj, A.; Rao, C. N. R. Angew. Chem., Int. Ed. 2013, 52, 13057-13061. doi:10.1002/anie.201306918

46. Min, S. X.; Lu, G. X. J. Phys. Chem. C 2011, 115, 13938-13945. doi:10.1021/jp203750z

47. Iwase, A.; Ng, Y. H.; Ishiguro, Y.; Kudo, A.; Amal, R. J. Am. Chem. Soc. 2011, 133, 11054-11057. doi:10.1021/ja203296z

48. Kaniyankandy, S.; Rawalekar, S.; Ghosh, H. N. J. Phys. Chem. C 2012, 116, 16271-16275. doi:10.1021/jp303712y

49. Lightcap, I. V.; Kamat, P. V. J. Am. Chem. Soc. 2012, 134, 7109-7116. doi:10.1021/ja3012929

50. Cao, A.; Liu, Z.; Chu, S.; Wu, M.; Ye, Z.; Cai, Z.; Chang, Y.; Wang, S.; Gong, Q.; Liu, Y. Adv. Mater. 2010, 22, 103-106. doi:10.1002/adma.200901920

51. Zhang, H.-H.; Feng, K.; Chen, B.; Meng, Q.-Y.; Li, Z.-J.; Tung, C.-H.; Wu, L.-Z. Catal. Sci. Technol. 2013, 3, 1815-1821. doi:10.1039/c3cy00098b 
52. Huang, W.; Ouyang, X.; Lee, L. J. ACS Nano 2012, 6, 10178-10185. doi:10.1021/nn303917p

53. Si, Y.; Samulski, E. T. Nano Lett. 2008, 8, 1679-1682. doi:10.1021/nl080604h

54. Stankovich, S.; Dikin, D. A.; Piner, R. D.; Kohlhaas, K. A.; Kleinhammes, A.; Jia, Y.; Wu, Y.; Nguyen, S. T.; Ruoff, R. S. Carbon 2007, 45, 1558-1565. doi:10.1016/j.carbon.2007.02.034

55. Ganguly, A.; Sharma, S.; Papakonstantinou, P.; Hamilton, J. J. Phys. Chem. C 2011, 115, 17009-17019. doi:10.1021/jp203741y

56. Hughes, M. N.; Rutt, K. J. J. Chem. Soc. A 1968, 0, 2788-2790. doi:10.1039/j19680002788

57. Dong, J. F.; Wang, M.; Li, X. Q.; Chen, L.; He, Y.; Sun, L. C. ChemSusChem 2012, 5, 2133-2138. doi:10.1002/cssc.201200490

58. Kamat, P. V. J. Phys. Chem. Lett. 2011, 2, 242-251. doi:10.1021/jz101639v

59. Williams, G.; Seger, B.; Kamat, P. V. ACS Nano 2008, 2, 1487-1491. doi:10.1021/nn800251f

60. Kongkanand, A.; Kamat, P. V. ACS Nano 2007, 1, 13-21. doi:10.1021/nn700036f

61. Zhu, M.; Li, Z.; Xiao, B.; Lu, Y.; Du, Y.; Yang, P.; Wang, X. ACS Appl. Mater. Interfaces 2013, 5, 1732-1740. doi:10.1021/am302912v

62. Zhou, J.; Tian, G.; Chen, Y.; Meng, X.; Shi, Y.; Cao, X.; Pan, K.; Fu, H. Chem. Commun. 2013, 49, 2237-2239. doi:10.1039/c3cc38999e

63. Mou, Z.; Yin, S.; Zhu, M.; Du, Y.; Wang, X.; Yang, P.; Zheng, J.; Lu, C. Phys. Chem. Chem. Phys. 2013, 15, 2793-2799. doi:10.1039/c2cp44270a

64. Valdes-Aguilera, O.; Neckers, D. C. Acc. Chem. Res. 1989, 22, 171-177. doi:10.1021/ar00161a002

65. Biesinger, M. C.; Payne, B. P.; Grosvenor, A. P.; Lau, L. W. M.; Gerson, A. R.; Smart, R. S. C. Appl. Surf. Sci. 2011, 257, 2717-2730. doi:10.1016/j.apsusc.2010.10.051

66. Bai, S.; Shen, X.; Zhu, G.; Li, M.; Xi, H.; Chen, K. ACS Appl. Mater. Interfaces 2012, 4, 2378-2386. doi:10.1021/am300310d

67. Sun, Y.; Bigi, J. P.; Piro, N. A.; Tang, M. L.; Long, J. R.; Chang, C. J. J. Am. Chem. Soc. 2011, 133, 9212-9215. doi:10.1021/ja202743r

68. Sharma, G. D.; Balraju, P.; Kumar, M.; Roy, M. S. Mater. Sci. Eng., B 2009, 162, 32-39. doi:10.1016/j.mseb.2009.01.033

69. Stubbert, B. D.; Peters, J. C.; Gray, H. B. J. Am. Chem. Soc. 2011, 133, 18070-18073. doi:10.1021/ja2078015

\section{License and Terms}

This is an Open Access article under the terms of the Creative Commons Attribution License

(http://creativecommons.org/licenses/by/2.0), which permits unrestricted use, distribution, and reproduction in any medium, provided the original work is properly cited.

The license is subject to the Beilstein Journal of Nanotechnology terms and conditions: (http://www.beilstein-journals.org/bjnano)

The definitive version of this article is the electronic one which can be found at:

doi:10.3762/bjnano.5.128 